Review

\title{
Recent Developments in the Reformatsky-Claisen Rearrangement
}

\section{Jun Ishihara * and Susumi Hatakeyama}

Graduate School of Biomedical Sciences, Nagasaki University, 1-14 Bunkyo-machi, Nagasaki 852-8521, Japan; E-Mail: susumi@nagasaki-u.ac.jp

* Author to whom correspondence should be addressed; E-Mail: jishi@nagasaki-u.ac.jp;

Tel.: +81-95-819-2427; Fax: +81-95-819-2426.

Received: 8 November 2012; in revised form: 21 November 2012 / Accepted: 27 November 2012 / Published: 30 November 2012

\begin{abstract}
The rearrangement of allyl $\alpha$-bromoacetates with $\mathrm{Zn}$ dust is known as the Reformatsky-Claisen rearrangement. Whereas the Ireland-Claisen rearrangement has been widely used in the synthesis of a diverse range of natural products, the Zn-mediated Reformatsky-Claisen rearrangement has not been utilized so often. In this article, we will provide an overview of recent advances in the Reformatsky-Claisen rearrangement field, including the In-mediated Reformatsky-Claisen rearrangement we have recently developed.
\end{abstract}

Keywords: Reformatsky-Claisen rearrangement; Reformatsky reaction; Claisen rearrangement; zinc; indium

\section{Introduction}

The development of new methods for stereoselective carbon-carbon bond formation has been important in the creation of useful molecules such as drugs and other chemical entities. [3,3]-Sigmatropic rearrangements are reliable reactions for selective carbon-carbon bond formation, in particular, the Claisen rearrangement is one of the most competent methods to provide useful building blocks for the synthesis of natural products [1-4]. The synthetic utility of this reaction has prompted the development of a considerable number of variants of the classical Claisen rearrangement [5-9]. For instance, zinc-mediated [3,3]-sigmatropic rearrangement of $\alpha$-haloesters, proceeding through $\mathrm{Zn}$ enolates, are referred to as the Reformatsky-Claisen rearrangement. Compared to the Ireland-Claisen rearrangement which was widely used in the synthesis of a diverse range of natural products [10-14], the Reformatsky-Claisen rearrangement has the advantage of being performed under non-basic 
conditions. This review article focuses on the chemistry of the Reformatsky-Claisen rearrangement and its applications, as well as the recent development of the In-mediated Reformatsky-Claisen rearrangement.

\section{Pioneering Works of the Reformatsky-Claisen Rearrangement}

In 1973, Baldwin and Walker reported a synthetically useful sigmatropic rearrangement of $\alpha$-halogenated allyl esters [15]. Zinc enolates, generated by Reformatsky-type reactions of $\alpha$-halogenated allyl esters with zinc dust, provided the corresponding rearranged products. For instance, when allyl $\alpha$-bromoisobutyrate 1a was added to a refluxing suspension of an excess amount of Zn dust it afforded acid 2a in excellent yield (Table 1). It should be noted that the rearrangement of $1 \mathbf{a}$ can readily install a quaternary center into the product. The reaction of $\alpha$-bromopropionate $\mathbf{1 b}$ also proceeded smoothly to give a rearranged product $\mathbf{2 b}$. In contrast, the rearrangement of simple allyl ester 1c and secondary ester 1d were found to be fruitless. Baldwin stated that one of the reasons for the low yield would be the generation of 1,3-dicarbonyl products by intermolecular Claisen condensation, which had been known as byproducts of classical Reformatsky reactions. Another reason would arise from the decomposion of $\mathrm{Zn}$ enolate 4 to afford 5 and allyl bromide (Scheme 1). The resulting allyl bromide would undergo Friedel-Crafts reaction with the aromatic solvent catalyzed by the zinc bromide generated in the reaction.

Table 1. Baldwin and Walker's pioneering work of the Reformatsky-Claisen rearrangement.<smiles>[R]C=CC([R9])OC(=O)C([R])(Br)Br</smiles>

1a-d

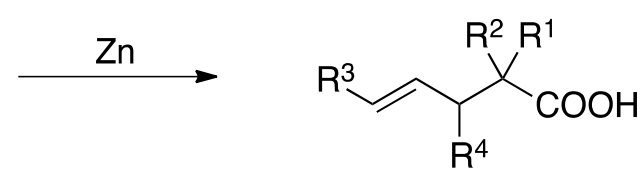

2a-d

\begin{tabular}{cccccccc}
\hline Substrate & $\mathbf{R}^{\mathbf{1}}$ & $\mathbf{R}^{\mathbf{2}}$ & $\mathbf{R}^{\mathbf{3}}$ & $\mathbf{R}^{\mathbf{4}}$ & Solvent & Temp $\left({ }^{\circ} \mathbf{C}\right)$ & Yield of 2a-d \\
\hline 1a & $\mathrm{Me}$ & $\mathrm{Me}$ & $\mathrm{H}$ & $\mathrm{H}$ & $\mathrm{PhH}$ & 80 & $100 \%$ \\
1b & $\mathrm{Me}$ & $\mathrm{H}$ & $\mathrm{H}$ & $\mathrm{Me}$ & $\mathrm{PhMe}$ & 110 & $96 \%$ \\
1c & $\mathrm{H}$ & $\mathrm{H}$ & $\mathrm{H}$ & $\mathrm{H}$ & Xylene & 140 & $<15 \%$ \\
$\mathbf{1 d}$ & $\mathrm{Me}$ & $\mathrm{H}$ & $\mathrm{Ph}$ & $\mathrm{H}$ & $\mathrm{PhMe}$ & 110 & $16 \%$ \\
\hline
\end{tabular}

Scheme 1. Possible pathway to generate byproduct.<smiles>[R]C(CC)=C(OCC=C)OCC=C</smiles>

\subsection{Reformatsky-Claisen Rearrangement in the Presence of Zinc and a Silylating Reagent}

The Reformatsky-Claisen rearrangement also proceeds in the presence of a silylating agent, in which a silyl ketene acetal is the most likely intermediate. Ireland and co-workers demonstrated that upon heating a mixture of $\alpha$-bromo ester $\mathbf{6}, \mathrm{Zn}$ dust, and TBSCl in THF and HMPA under reflux, the 
carboxylic acid 7 was obtained in 73\% yield (Scheme 2) [11]. This reaction would be evaluated as a basefree reaction complementary to the ester enolate Claisen rearrangement.

Scheme 2. Reformatsky-Claisen rearrangement with zinc and a silylating reagent.

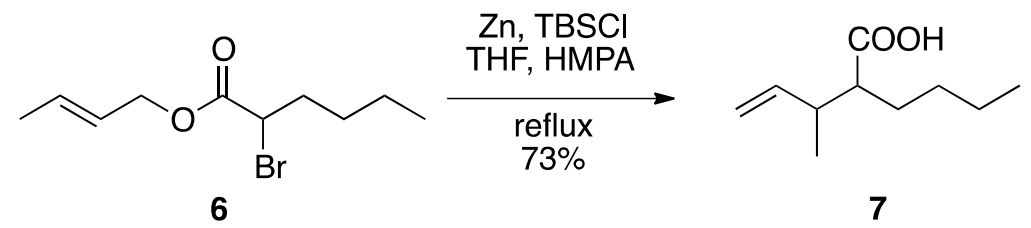

An example of a reactions performed under these conditions was illustrated by Akiba, which involves preparation of a carboxylic acid bearing a silyl group [16]. A thermal reaction of $\alpha$-bromoacetate 8a with $\mathrm{Zn}$ and $\mathrm{TBSCl}$ in THF and HMPA provided carboxylic acid 9, $\mathrm{LiAlH}_{4}$ reduction of which afforded alcohol $\mathbf{1 0}$ in $68 \%$ overall yield. On the other hand, application of the Ireland-Claisen protocol to acetate $\mathbf{8 b}$ resulted in the production of the same carboxylic acid $\mathbf{9}$ in lower yield (Scheme 3).

Scheme 3. Reformatsky-Claisen rearrangement of 8a.

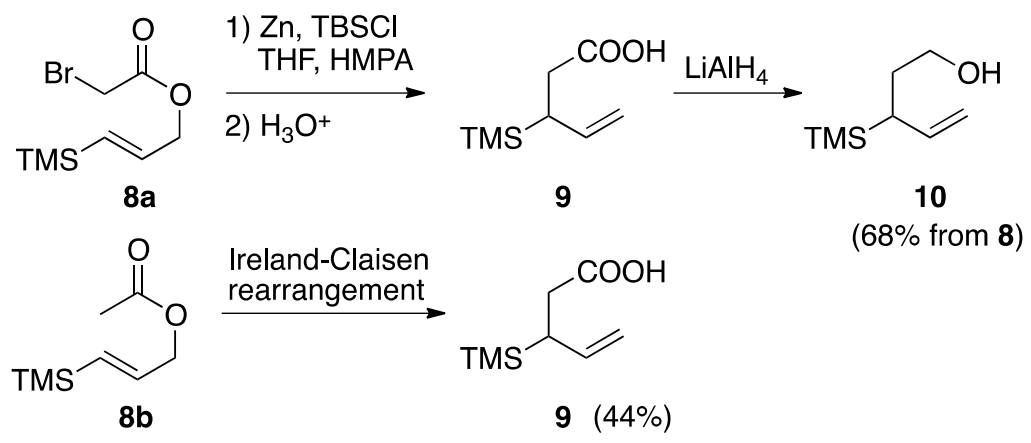

Narasaka and co-workers employed the Reformatsky-Claisen rearrangement for the preparation of highly functionalized carboxylic acid 12. Exposure of $\alpha$-bromoisobutyrate $\mathbf{1 1}$ to $\mathrm{Zn}$ and TMSCl furnished branched acid 12, having a quaternary carbon. The product 12 was transformed to a dienyl oxime 13, which was a precursor in a palladium-catalyzed domino cyclization (Scheme 4) [17].

Scheme 4. Preparation of functionalized carboxylic acid 12.

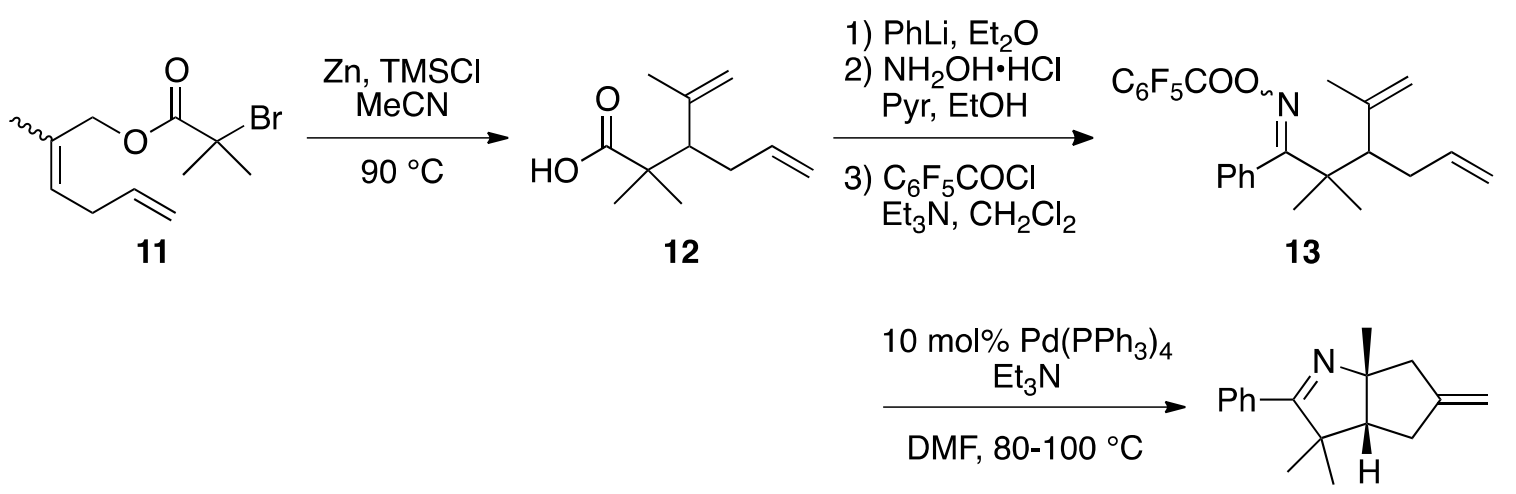




\subsection{Application of Reformatsky-Claisen Rearrangement with Zinc and a Silylating Reagent}

The most frequently reported Reformatsky-Claisen protocol involves heating a substrate with $\mathrm{Zn}$ dust and a silylating reagent in an aprotic polar solvent. Several additional applications are described below.

\subsubsection{Preparation of $\alpha$-Fluorocarboxylic Acid by Reformatsky-Claisen Rearrangement}

Fluorinated ketones have been successfully employed as enzyme inhibitors in modern bioorganic chemistry. Therefore, the synthesis of selectively fluorinated molecules which have fluorine substituents adjacent to a carbonyl group became a major target in fluoroorganic chemistry. One of the earliest applications of Reformatsky-Claisen rearrangement of fluorinated substrates, reported by Lang and co-workers, was the conversion of allyl chlorodifluoroacetate 14 to difluoroacid 15 (Scheme 5). Various allyl chlorodifluoroacetates can undergo a Reformatsky-Claisen protocol to give 2,2-difluoro4-pentenoic acid derivatives [18].

Scheme 5. Reformatsky-Claisen reaction of fluorinated substrate 14.

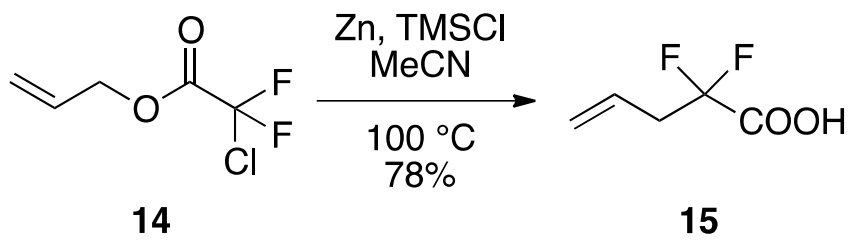

2.2.2. Application of $\alpha$-Fluorocarboxylic Acid Induced by Reformatsky-Claisen Rearrangement to Biological Active Compounds

An intriguing extension of this methodology would be found in the synthesis of a key building block for a number of second-generation HIV protease inhibitors reported by Chen's group at Pfizer. They performed the reaction of chlorodifluoro derivative 16 with $\mathrm{Zn}$ and $\mathrm{TMSCl}$ in 1,3-dimethylimidazolidin-2-one (DMI) for the preparation of difluorocarboxylic acid 17. The product $\mathbf{1 7}$ was then converted to amide 18, from which 4,4-difluoro-3,3-dimethylproline derivative 19, a core part of HIV protease inhibitors such as $\mathbf{2 0}$ and $\mathbf{2 1}$ was synthesized (Scheme 6) [19].

Scheme 6. Synthesis of 2,2-Difluoroproline Derivative by Reformatsky-Claisen Rearrangement.
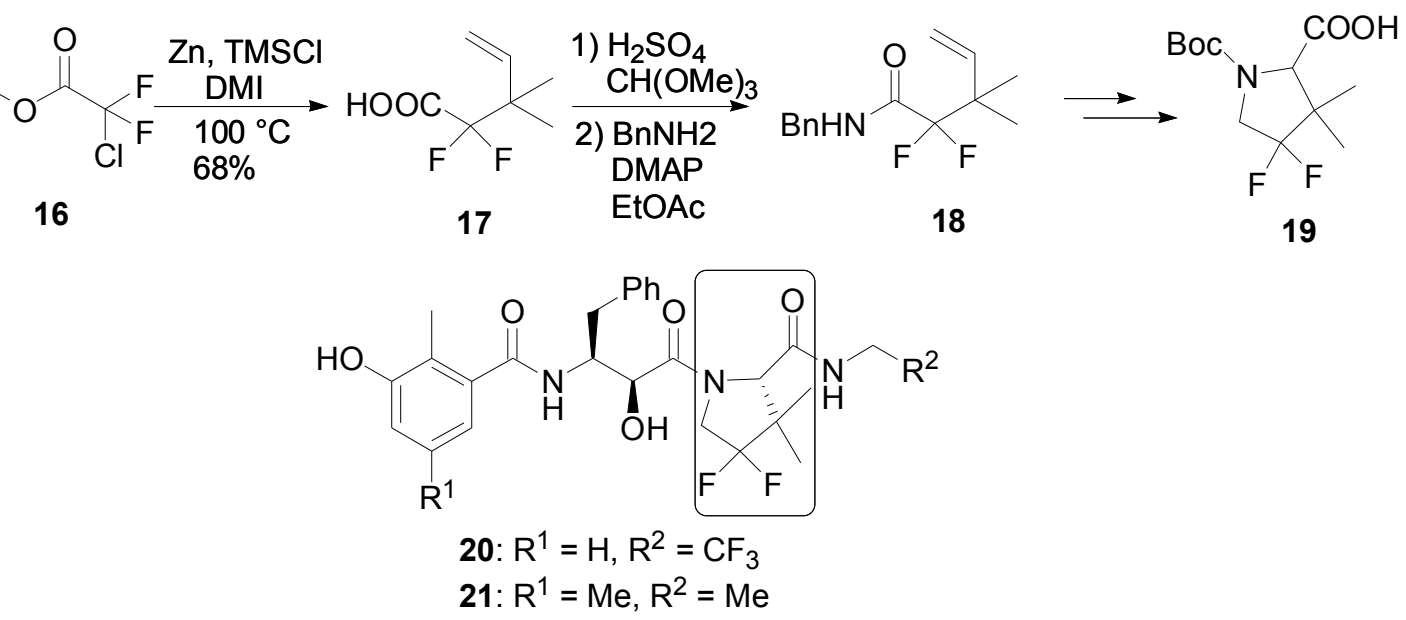
Qing and co-workers employed a Reformatsky-Claisen rearrangement to synthesize fluorinated thionucleosides. The replacement of a carbohydrate moiety of naturally occurring nucleosides with other five membered rings is one of the promising approaches for exerting a significant effect on the biologic activity. In the course of the studies of nucleoside analogues, they targeted difluoromethylene containing thionucleosides, such as $\mathbf{2 2}$ and $\mathbf{2 3}$, which were the modified analogs of highly bioactive (-)-2'-deoxy-3'-thiacytidine (3TC) and (+)-2'-deoxy-3'-oxacytidine (L-OddC) (Scheme 7) [20]. When Reformatsky-Claisen rearrangement of $\mathbf{2 4}$ was carried out under conventional conditions ( $\mathrm{Zn}$, and $\mathrm{TMSCl}$ ), none of desired product was obtained. On the other hand, the addition of pyridine promoted this rearrangement effectively. Thus, treatment of $\mathbf{2 4}$ with $\mathrm{Zn}$ and $\mathrm{TMSCl}$ in the presence of pyridine at $120{ }^{\circ} \mathrm{C}$ in a sealed tube afforded the desired product 25 in $43 \%$ yield. Compound 25 was then transformed to thiofuranose $\mathbf{2 6}$ in 4 steps, which was condensed with pyrimidine bases by regioselective Pummerer reaction to afford nucleosides 27a and 27b (Scheme 7).

Scheme 7. Synthesis of thionucleosides through Reformatsky-Claisen Rearrangement by Qing.<smiles>Nc1ccn([C@H]2CS[C@@H](CO)O2)c(=O)n1</smiles>

3TC<smiles>Nc1ccn([C@@H]2CO[C@@H](CO)O2)c(=O)n1</smiles>

L-OddC<smiles>OC[C@@H]1CS[C@@H]([18OH])C1(F)F</smiles>

22a<smiles>OC[C@@H]1CSC([18OH])C1(F)F</smiles>

22b<smiles>[R16][R18][C@@H]1SC[C@@H](CO)C1(F)F</smiles><smiles>OC[C@@H]1CS[C@@H]([18OH])C1(F)F</smiles>

23b

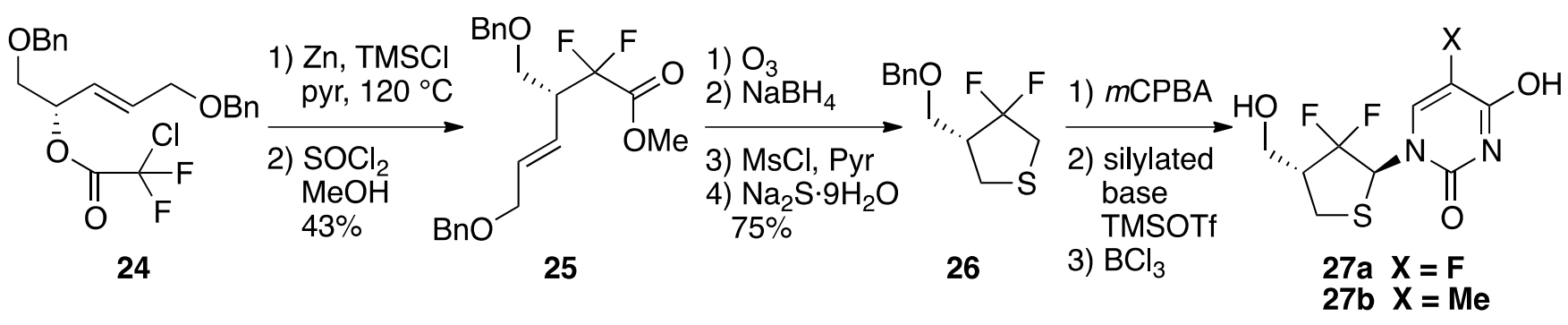

Qing's group further targeted fluorinated carbocyclic nucleosides based on the similar strategy. Upon treatment of 28 with $\mathrm{Zn}$ and $\mathrm{TMSCl}$ at $105^{\circ} \mathrm{C}$ in $\mathrm{MeCN}$, the rearrangement took place to deliver difluorinated acids, esterification of which afforded ethyl ester 29 as a mixture (syn:anti $=3: 1)$ in $72 \%$ yield [21]. On the other hand, the reaction of monofluoro ester $\mathbf{3 1}$ provided four isomers $(d r=8.7: 3.4: 1.8: 1)$, major component of which was syn-anti-product $\mathbf{3 2}$. The resulting esters $\mathbf{2 9}$ and 32 were convertible to cyclopentenes 30a,b, and 33a-c after installation of nucleobases, respectively (Scheme 8) [22]. 
Scheme 8. Synthesis of carbocyclic nucleosides by Qing.

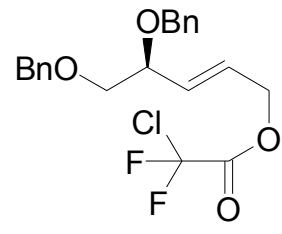

28

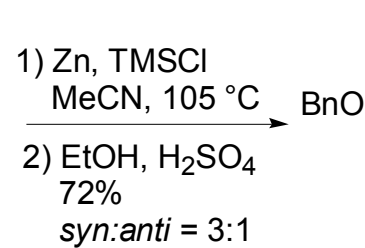

syn:anti $=3: 1$<smiles>C=CC(COCC)C(F)(C(=O)OCC)C(=O)OCC</smiles>

29<smiles>[R]c1cn(C2C=CC(F)(F)C2CO)c(=O)nc1O</smiles><smiles>O=C(OC/C=C/C(COc1ccccc1)OCc1ccccc1)C(F)F</smiles>

31

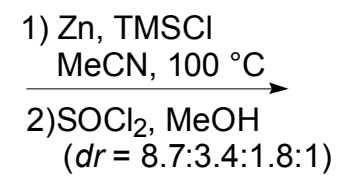

$(d r=8.7: 3.4: 1.8: 1)$<smiles>Brc1ccccc1</smiles>

$32(45 \%)$

\section{Indium-Mediated Reformatsky-Claisen Rearrangement}

Recently Ishihara and Hatakeyama reported the In-mediated Reformatsky-Claisen rearrangement, which is feasible for various $\alpha$-bromoisobutyrate derivatives [23,24]. Initially, $\alpha$-bromocyclohexanecarboxylate $\mathbf{3 4}$ was subjected to the conventional rearrangement conditions. However,

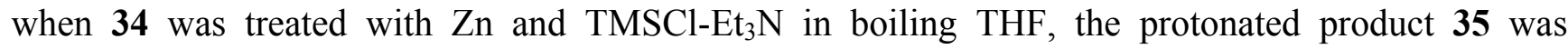
obtained exclusively (Scheme 9). The scope of the Reformatsky reaction has been considerably extended by the use of metals other than $\mathrm{Zn}$. For instance, in is known to react readily with $\alpha$-halo esters to induce the Reformatsky-type reaction [25]. Recently Baba and co-workers demonstrated that $\operatorname{In}(\mathrm{I}) \mathrm{X}$ is effective for the Reformatsky-type reactions of ketones and esters to afford $\beta$-hydroxyketones and $\beta$-hydroxyesters diastereoselectively [26-28]. Gratifyingly, we found that

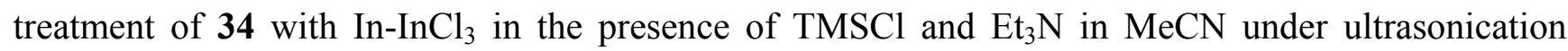
conditions at $10-30{ }^{\circ} \mathrm{C}$ furnished 36 in $88 \%$ yield.

Scheme 9. Reformatsky-Claisen rearrangement of $\mathbf{3 4}$.<smiles>C=CCOC(=O)C1(Br)CCCCC1</smiles>

34

34

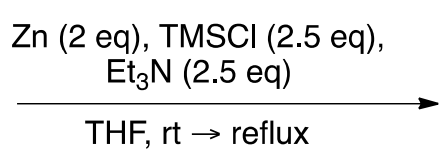

$(100 \%)$

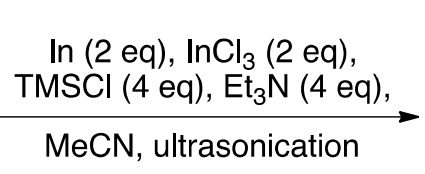

$(88 \%)$<smiles>C=CCOC(=O)C1CCCCC1</smiles><smiles>C=CCC1(C(=O)O)CCCCC1</smiles>

36

\subsection{Indium-Mediated Reformatsky-Claisen Rearrangement of $\alpha$-Bromopropionates}

To probe the generality of the In-mediated reaction, $\alpha$-bromoesters $\mathbf{3 7 a}-\mathbf{c}$ were subjected to the optimized reaction conditions (Scheme 10). The benzyl and TBS ethers were also not affected at all under the conditions; however the THP group was susceptible owing to the Lewis acidity of $\mathrm{InCl}_{3}$. 
Scheme 10. Indium-mediated Reformatsky-Claisen rearrangement.
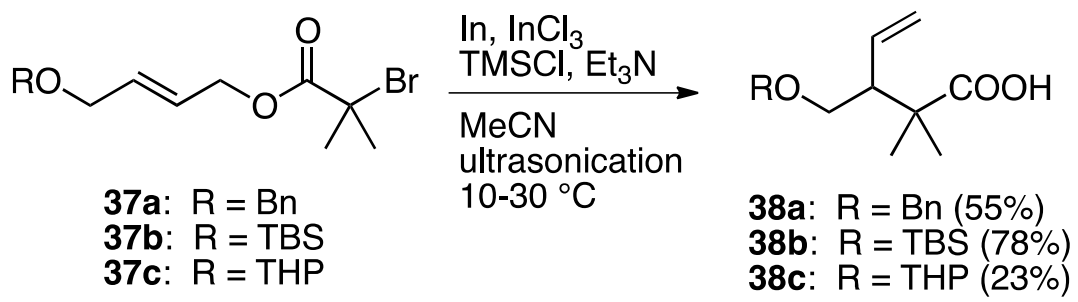

\subsection{Indium-Mediated Reformatsky-Claisen Rearrangement of Various Substrates}

We next turned our attention to the reactions of various $\alpha$-bromopropionate derivatives, which are readily prepared by acylation of the corresponding allylic alcohols with 2-bromoisobutyryl bromide or 2-bromopropionyl bromide (Table 2). Most reactions afforded the rearranged products along with the protonated compounds.

Table 2. Indium-mediated Reformatsky-Claisen Rearrangement of Various Substrates.

(39):

Method a: In (2 eq.), $\mathrm{InCl}_{3}$ (2 eq.), TMSCl (8 eq.), $\mathrm{Et}_{3} \mathrm{~N}$ (8 eq.), $\mathrm{MeCN}, 10-30{ }^{\circ} \mathrm{C}$; Method b: In (2 eq.), $\mathrm{InCl}_{3}$ ( 2 eq.), $\mathrm{TMSCl}$ (4 eq.), $\mathrm{Et}_{3} \mathrm{~N}$ (4 eq.), THF-DMPU (1:1), 10-30 ${ }^{\circ} \mathrm{C}$.

The aromatic compounds 39, 41, and $\mathbf{4 3}$ underwent rearrangement to carboxylic acids $\mathbf{4 0 , 4 2}$, and 44 in moderate to excellent yields, although the diastereoselectivities were poor. In the case of 39a, 41a, and 43a, the rearrangement took place in $\mathrm{MeCN}$ rather smoothly, whereas the rearrangement of 39b, 41b, and 43b proceeded in THF-DMPU (1:1) but not in MeCN. On the other hand, the reactions of aliphatic substrates $\mathbf{4 5}$ and $\mathbf{4 7}$ brought about the Reformatsky-Claisen rearrangement successfully to give highly functionalized carboxylic acids $\mathbf{4 6}$ and 48. In fact, when the In-mediated reaction of bulky 2-methylbut-3-en-2-yl esters $45 \mathbf{a}$ and $\mathbf{4 5 b}$ were performed, compounds $\mathbf{4 6 a}$ and $\mathbf{4 6}$ b were obtained in 
$63 \%$ and $62 \%$ yields, respectively. Notably, the rearrangement of 47 a can install contiguous quaternary centers, giving compound $\mathbf{4 8 a}$ in $91 \%$ yield.

\subsection{The Reaction of Base-Sensitive Compounds}

The most intriguing feature of the Reformatsky-Claisen rearrangement is the feasibility of utilizing base-sensitive substrates. The reactions of $\alpha$-bromoisobutyrates E-49 and Z-49 under the optimized conditions proceeded smoothly to afford 50 in $80 \%$ and $53 \%$ yields, respectively (Scheme 11). In the case of $\alpha$-bromopropionate 51, a moderate diastereoselectivity was observed, although the yield was not satisfying. On the other hand, the reaction of 53 afforded carboxylic acid 54 having contiguous quaternary carbons in $66 \%$ yield. It should be noted that the acetoxy group could survive under the reaction conditions in stark contrast to the Ireland-Claisen rearrangement.

Scheme 11. Investigation of the Reformatsky-Claisen rearrangement of acetoxy $\alpha$-bromoesters.<smiles></smiles>

$E-46$<smiles>CC(=O)OC/C=C\COC(=O)C(C)(C)Br</smiles>

Z-46
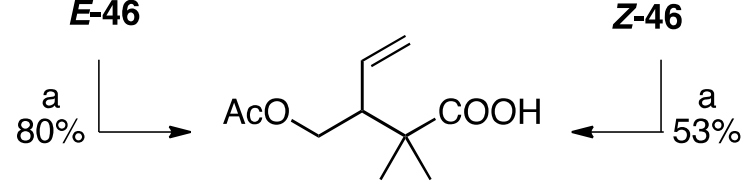

47<smiles>CC(=O)OC/C=C/COC(=O)C(C)Br</smiles>

48

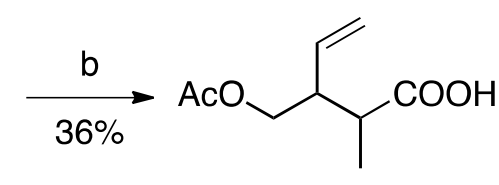

$49 \quad(3.3: 1)$<smiles>C=CC(C)(COC(=O)C=C(Br)Br)C(C)(C)C(=O)O</smiles>

50

Reactions and conditions: (a) In (2 eq.), $\mathrm{InCl}_{3}$ ( 2 eq.), $\mathrm{TMSCl}$ ( 8 eq.), $\mathrm{Et}_{3} \mathrm{~N}$ ( 8 eq.), $\mathrm{MeCN}$, ultrasonication, $10-30{ }^{\circ} \mathrm{C}$; (b) In ( 2 eq.), $\mathrm{InCl}_{3}$ ( 2 eq.), $\mathrm{TMSCl}\left(8\right.$ eq.), $\mathrm{Et}_{3} \mathrm{~N}$ (8 eq.), THF-DMF (1:1) ultrasonication, $10-30{ }^{\circ} \mathrm{C}$.

The results shown in Scheme 12 reveals a marked advantage over the Ireland-Claisen rearrangement. Thus, when the reaction of $\mathbf{5 5}$ was performed under the above mentioned In-mediated rearrangement conditions, the rearranged product 56 was obtained in 64\% yield. In contrast, the reaction of 57 with KHMDS in the presence of TMSCl and $\mathrm{Et}_{3} \mathrm{~N}$ afforded isomer 58 in place of 56 [29-31]. 
Scheme 12. Attempted rearrangements of 55 and 57.

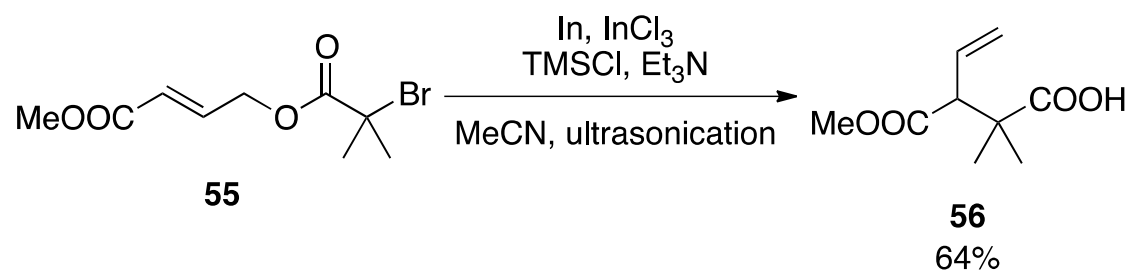

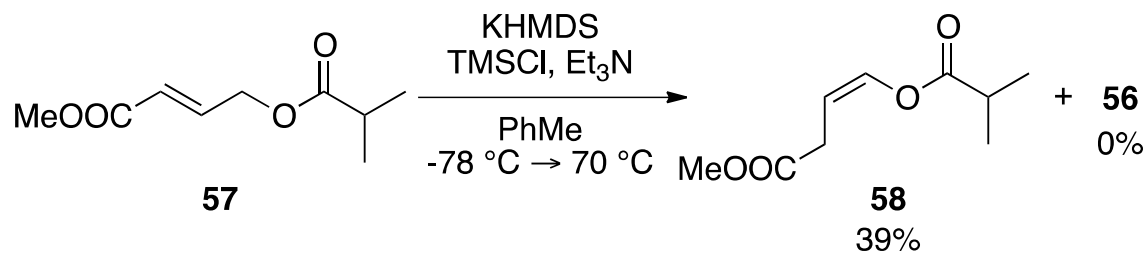

\subsection{Proposed Mechanism of the Indium-Mediated Reformatsky-Claisen Rearrangement}

As illustrated in Scheme 13, it has been reported that a mixture of $\mathrm{In}$ and $\mathrm{InCl}_{3}$ generates $\mathrm{InCl}$ (I) in situ, which readily reacts with $\alpha$-bromoacetate 59 to afford $\alpha$-In(III) intermediate 60 or $\alpha$-In(I) 61 [27]. Both $\alpha$-indium intermediates can be transformed to the In enolate 62, which is converted to silyl ketene acetal 63 by silylation. Since no rearrangement was observed without $\mathrm{TMSCl}$ and $\mathrm{Et}_{3} \mathrm{~N}$, the direct rearrangement of In enolates seems unlikely. Finally, the rearrangement of 63 proceeds to generate the corresponding carboxylic acid 64. The rearrangement of $\alpha$-bromoisobutyrate derivatives $\left(\mathrm{R}_{3}, \mathrm{R}_{4}=\mathrm{Me}\right)$ smoothly proceeded in $\mathrm{MeCN}$, whereas the reaction of $\alpha$-bromopropionates $\left(\mathrm{R}_{3}=\mathrm{Me}, \mathrm{R}_{4}=\mathrm{H}\right)$ in $\mathrm{MeCN}$ afforded only the protonated products. These results can be rationalized as follows: compared to enolate $62\left(\mathrm{R}_{3}, \mathrm{R}_{4}=\mathrm{Me}\right)$ derived from isobutyrate, the enolate $\mathbf{6 2}$ derived from the propionate derivative $\left(\mathrm{R}_{3}=\mathrm{Me}, \mathrm{R}_{4}=\mathrm{H}\right)$ is more nucleophilic, so it easily undergoes protonation with MeCN to form a protonated product. The deuteration experiment in $\mathrm{MeCN}-\mathrm{d}_{3}$ clearly supported that the rearrangement would proceed, provided that the protonation of an enolate is relatively slow.

Scheme 13. Proposed mechanism of Reformatsky-Claisen rearrangement.

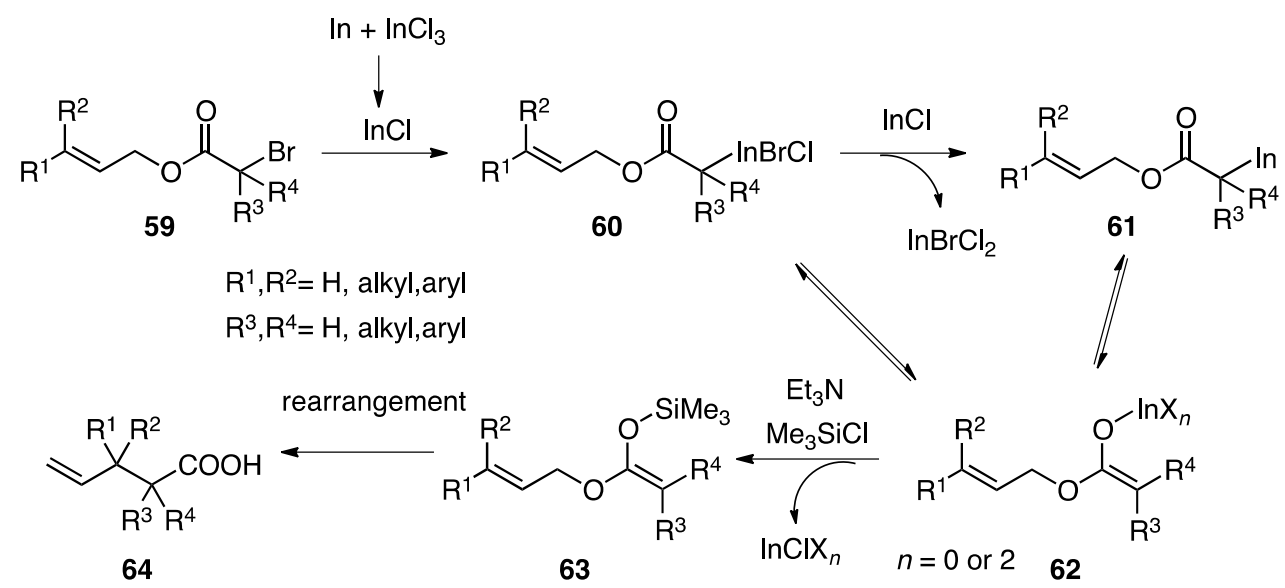

\section{Conclusions}

The recent studies show that $\mathrm{Zn}$ - and In-mediated Reformatsky-Claisen rearrangements of $\alpha$-haloacetate derivatives are regarded as a useful variant of the classical Ireland-Claisen 
rearranegements. The feasibility of these methods for base-sensitive substrates makes it complementary to the Ireland-Claisen rearrangement, and allows simple access to valuable building blocks for the synthesis of complex natural products.

\section{Acknowledgments}

This work was financially supported by Grants-in-Aid for Scientific Research from the Ministry of Education, Culture, Sports, Science and Technology, Japan (24590011).

\section{References}

1. Ziegler, F.E. Stereo- and regiochemistry of the Claisen rearrangement: Applications to natural products synthesis. Acc. Chem. Res. 1977, 10, 227-232.

2. Tadano, K.-I. Natural products synthesis starting with carbohydrates based on the Claisen rearrangement protocol. In Studies in Natural Products Chemistry: Stereoselective Synthesis (Part F); Atta-Ur-Rahman, Ed.; Elsevier: Amsterdam, The Netherlands, 1992; Volume 10, pp. 405-455.

3. Ilardi, E.A.; Stivala, C.E.; Zakarian, A. [3,3]-Sigmatropic rearrangements: Recent applications in the total synthesis of natural products. Chem. Soc. Rev. 2009, 38, 3133-3148.

4. Kotha, S.; Krishna, N.G.; Halder, S.; Misra, S. A synergistic approach to polycyclics via a strategic utilization of Claisen rearrangement and olefin metathesis. Org. Biomol. Chem. 2011, 9, 5597-5624.

5. Hiersemann, M., Nubbemeyer, U., Eds. The Claisen Rearrangement: Methods and Applications; Wiley-VCH Verlag GmbH \& Co. KGaA: Weinheim, Germany, 2007.

6. Bennett, G.B. The Claisen rearrangement in organic synthesis: 1967 to January 1977. Synthesis 1977, 589-606.

7. Blechert, S. The hetero-Cope rearrangement in organic synthesis. Synthesis 1989, 71-82.

8. Wipf, P. Claisen rearrangements. In Comprehensive Organic synthesis; Trost, B.M., Ed.; Pergamon Press: Oxford, UK, 1991; Volume 5, pp. 827-873.

9. Martin Castro, A.M. Claisen rearrangement over the past nine decades. Chem. Rev. 2004, 104, 2939.

10. Ireland, R.E.; Mueller, R.H. Claisen rearrangement of allyl esters. J. Am. Chem. Soc. 1972, 94, 5897-5898.

11. Ireland, R.E.; Mueller, R.H.; Willard, A.K. The ester enolate Claisen rearrangement. Stereochemical control through stereoselective enolate formation. J. Am. Chem. Soc. 1976, 98, 2868-2877.

12. Ireland, R.E.; Wipf, P.; Armstrong, J.D. Stereochemical control in the ester enolate Claisen rearrangement. 1. Stereoselectivity in silyl ketene acetal formation. J. Org. Chem. 1991, 56, 650-657.

13. Ireland, R.E.; Wipf, P.; Xiang, J.-N. Stereochemical control in the ester enolate Claisen rearrangement. 2. Chairlike vs boatlike transition-state selection. J. Org. Chem. 1991, 56, 3572-3582.

14. Pereira, S.; Srebnik, M. The Ireland-Claisen rearrangement. Aldrichim. Acta 1993, 26, 17-29.

15. Baldwin, J.E.; Walker, J.A. The Reformatsky-Claisen reaction, A new synthetically useful sigmatropic process. J. Chem. Soc. Chem. Commun. 1973, 117-118.

16. Wada, M.; Shigehisa, T.; Akiba, K. A new synthesis of medium-membered lactones via intramolecular condensation of $\alpha$-chlorosulfides containing an ester group and allylsilanyl moiety. Tetrahedron Lett. 1985, 26, 5191-5194. 
17. Zaman, S.; Kitamura, M.; Narasaka, K. Synthesis of polycyclic imines by palladium-catalyzed domino cyclization of di- and trienyl ketone O-pentafluorobenzoyloximes. Bull. Chem. Soc. Jpn. 2003, 76, 1055-1062.

18. Greuter, H.; Lang, R.W.; Romann, A.J. Fluorine-containing organozinc reagents. V. ${ }^{1}$ : The Reformatskii-claisen reaction of chlorodifluoroacetic acid derivatives. Tetrahedron Lett. 1988, 29, 3291-3294.

19. Chen, L.; Kim, Y.M.; Kucera, D.J.; Harrison, K.E.; Bahmanyar, S.; Scott, J.M.; Yazbeck, D. Fluorination-free synthesis of a 4,4-difluoro-3,3-dimethylproline derivative. J. Org. Chem. 2006, $71,5468-5473$.

20. Zheng, F.; Zhang, X.; Qing, F.-L. Stereoselective Reformatskii-Claisen rearrangement: Synthesis of 2',3'-dideoxy-6',6'-difluoro-2'-thionucleosides. Chem. Commun. 2009, 1505-1507.

21. Yang, Y.-Y.; Xu, J.; You, Z.-W.; Xu, X.-H.; Qiu, X.-L.; Qing, F.-L. Synthesis of 3',3'-difluoro2'-hydroxymethyl-4',5'-unsaturated carbocyclic nucleosides. Org. Lett. 2007, 9, 5437-5440.

22. Yang, Y.; Zheng, F.; Qing, F.-L. Synthesis of 2',3'-dideoxy-6'-fluorocarbocyclic nucleosides via Reformatskii-Claisen rearrangement. Tetrahedron 2011, 67, 3388-3394.

23. Ishihara, J.; Koyama, N.; Nishino, Y.; Takahashi, K.; Hatakeyama, S. A new variant of Reformatsky-Claisen rearrangement mediated by indium chloride. Synlett 2009, 2351-2355.

24. Ishihara, J.; Watanabe, Y.; Koyama, N.; Nishino, Y.; Takahashi, K.; Hatakeyama, S. Indium-mediated Reformatsky-Claisen rearrangement. Tetrahedron 2011, 67, 3659-3667.

25. Chao, L.-C.; Rieke, R.D. Activated metals. IX. New reformatsky reagent involving activated indium for the preparation of $\beta$-hydroxy esters. J. Org. Chem. 1975, 40, 2253-2255.

26. Babu, S.A.; Yasuda, M.; Shibata, I.; Baba, A. In- or In(I)-Employed diastereoselective Reformatsky-type reactions with ketones: ${ }^{1} \mathrm{H}-\mathrm{NMR}$ investigations on the active species. Org. Lett. 2004, 6, 4475-4478.

27. Babu, S.A.; Yasuda, M.; Shibata, I.; Baba, A. In- or In(I)-employed tailoring of the stereogenic centers in the Reformatsky-type reactions of simple ketones, $\alpha$-alkoxy ketones, and $\beta$-keto esters. J. Org. Chem. 2005, 70, 10408-10419.

28. Babu, S.A.; Yasuda, M.; Okabe, Y.; Shibata, I.; Baba, A. High chelation control of three contiguous stereogenic centers in the Reformatsky reactions of indium enolates with $\alpha$-hydroxy ketones: Unexpected stereochemistry of lactone formation. Org. Lett. 2006, 8, 3029-3032.

29. Inomata, K.; Hirata, T.; Sasada, Y.; Asada, T.; Senda, H.; Kinoshita, H. Crystallographic approach to the origin of "syn-effect". Chem. Lett. 1990, 2153-2156.

30. Hirata, T.; Sasada, Y.; Ohtani, T.; Asada, T.; Kinoshita, H.; Senda, H.; Inomata, K. "Syn-effect" in the conversion of $(E)$-vinylic sulfones to the corresponding allylic sulfones. Bull. Chem. Soc. Jpn. 1992, 65, 75-96.

31. Inomata, K. "Syn-effect" in the base-induced isomerization of vinylic sulfones to allylic sulfones and the related various reactions. J. Synth. Org. Chem. Jpn. 2009, 67, 1172-1182.

(C) 2012 by the authors; licensee MDPI, Basel, Switzerland. This article is an open access article distributed under the terms and conditions of the Creative Commons Attribution license (http://creativecommons.org/licenses/by/3.0/). 